\title{
AP-MOVPE Technology and Characterization of InGaAsN p-i-n Subcell for InGaAsN/GaAs Tandem Solar Cell
}

\author{
Wojciech Dawidowski, Beata Ściana, Iwona Zborowska-Lindert, Miroslav Mikolášek, Magdalena Latkowska, \\ Damian Radziewicz, Damian Pucicki, Katarzyna Bielak, Mikołaj Badura, Jaroslav Kováč, and Marek Tłaczała
}

\begin{abstract}
Tandem (two p-n junctions connected by tunnel junction) and multijunction solar cells (MJSCs) based on AIIIBV semiconductor compounds and alloys are the most effective photovoltaic devices. Record efficiency of the MJSCs exceeds 44\% under concentrated sunlight. Individual subcells connected in series by tunnel junctions are crucial components of these devices. In this paper we present atmospheric pressure metal organic vapour phase epitaxy (AP-MOVPE) of InGaAsN based subcell for InGaAsN/GaAs tandem solar cell. The parameters of epitaxial structure (optical and electrical), fabrication process of the test solar cell devices and current-voltage $(\mathrm{J}-\mathrm{V})$ characteristics are presented and discussed.
\end{abstract}

Keywords-dilute nitrides, AP-MOVPE, subcell, tandem solar cell, J-V characteristics

\section{INTRODUCTION}

$\mathbf{T}$ HE EFFICIENCY of solar cells (SCs) based on an ideal p-n junction is physically limited by Shockley-Queisser limit (deeply based on the second law of thermodynamics) to $33.7 \%$ [1]. The major factors responsible for energy loss in semiconductor SCs are a lack of absorption if the photon energy is smaller than the bandgap (mainly infrared radiation) and thermalization of photons with energy exceeding the bandgap (ultraviolet radiation). This causes the loss of about half of incident sunlight in solar cell conversion [2] and can be overcome by:

- splitting the sunlight spectrum into smaller energy bands and absorbing each of these bands by a cell of appropriate bandgap (multijunction solar cells) [3];

This work was co-financed by Wrocław University of Technology statutory grant and Slovak-Polish International Cooperation Program no. SK-PL-000512. In addition, W.D. acknowledges the financial support from the European Union within European Social Fund.

W. Dawidowski, B. Ściana, I. Zborowska-Lindert, D. Radziewicz, D. Pucicki, K. Bielak, M. Badura, and M. Tłaczała are with the Division of Microelectronics and Nanotechnology, Faculty of Microsystem Electronics and Photonics, Wrocław University of Technology, Z. Janiszewskiego 11/17, 50-372 Wrocław, Poland (see http://www.wemif.pwr.wroc.pl, e-mails: \{wojciech.dawidowski; beata.sciana; iwona.zborowska-lindert, damian.radziewicz, damian.pucicki, katarzyna.bielak, mikolaj.badura, marek.tlaczala\}@pwr.edu.pl).

M. Mikolášek and J. Kováč are with the Institute of Electronics and Photonics, Faculty of Electrical Engineering and Information Technology, Slovak University of Technology in Bratislava, Ilkovicova 3, 81219 Bratislava, Slovakia (see www.fei.stuba.sk, e-mails: \{miroslav.mikolasek; jaroslav.kovac @ stuba.sk).

M. Latkowska is with the Institute of Physics, Wrocław University of Technology, Wybrzeże Wyspiańskiego 27, 50-370, Poland (see http://www.if.pwr.wroc.pl/, e-mail: magdalena.latkowska@pwr.edu.pl).
- using multiple energy levels (inside the bandgap) for absorbing different ranges of solar spectrum (localized levels or intermediate bands) [4];

- multiple electron-hole pair generation by absorbed high energy photon (down-conversion) [5];

- generation of carrier pair by multiple absorption of low energy photons (up-conversion) [6];

- utilizing of nanometallic particles for light absorption enhancement (plasmonics) [7];

- hot carriers management before their thermalisation [8]. All mentioned methods for improving solar cell conversion efficiency can be applied for AIIIBV based solar cells. AIIIBV semiconductor compounds are characterized by direct bandgap, high value of the absorption coefficient, high resistivity against ionizing radiation, elaborated and reproducible epitaxial technology.

In this paper the fabrication and measurements of epitaxial and device structures of InGaAsN-based p-i-n subcell are presented. InGaAsN is a semiconductor compound which belongs to new group of semiconducting materials known as dilute nitrides (AIIIBV-N). These alloys have been intensively investigated since more than 20 years [9], [10]. Partial replacement of arsenic with nitrogen in GaAs matrix causes significant reduction of band gap energy, even to $150 \mathrm{meV}$ per $1 \%$ of incorporated $\mathrm{N}$, simultaneously it deteriorates the structural and optical quality of GaAsN compound. Introducing the indium to GaAsN alloy still results in decreasing the bandgap energy of InGaAsN alloy, concurrently the incorporation of In improve the optical and structural properties of dilute nitride semiconductor. By controlling the amount of introduced In and $\mathrm{N}$ into GaAs we are able to continuously change the band gap value of quaternary InGaAsN alloy and positions of conduction and valence band gap edges. For 3:1 ratio of indium to nitrogen in InGaAsN compound, we are able to obtain material which is lattice-matched to GaAs, AlAs, $\mathrm{In}_{0.5} \mathrm{Ga}_{0.5} \mathrm{P}$ and $\mathrm{Ge}$. It enables the epitaxial growth of latticematched layers consisted of different (with unlike bandgaps) semiconductor alloys - it in turn allows to design and growth semiconductor heterostructures, which are the heart of every optoelectronic device.

\section{Growth of InGAASN-BASED SUbCELL}

The epitaxial p-i-n structure of InGaAsN subcell was grown by atmospheric pressure metal organic vapour phase epitaxy (AP-MOVPE) using AIX 200 R\&D horizontal reactor on n-type GaAs ( $\mathrm{Si}$ doped) substrate. As a growth 
precursors were used trimethylgallium (TMGa - $\left.\mathrm{Ga}\left(\mathrm{CH}_{3}\right)_{3}\right)$, trimethylindium (TMIn - $\operatorname{In}\left(\mathrm{CH}_{3}\right)_{3}$ ), tertiarybutylhydrazine (TBHy - $\left.\left(\mathrm{C}_{4} \mathrm{H}_{9}\right) \mathrm{HN}_{2} \mathrm{H}_{2}\right)$ ) and $10 \%$ mixture of $\mathrm{AsH}_{3}$ in $\mathrm{H}_{2}$. As a dopant sources were used silane (20 ppm of $\mathrm{SiH}_{4}$ in $\mathrm{H}_{2}$ ) and diethylzinc (DEZn - $\left.\mathrm{Zn}\left(\mathrm{C}_{2} \mathrm{H}_{5}\right)_{2}\right)$ as a n-type and p-type dopants, respectively. High purity hydrogen (i.e. 99.9999\%) was employed as a carrier gas. Details of the growth process can be found elsewhere [11], [12], [13]. The active region of p-i-n solar cell (marked with gray in Fig. 1) consists of undoped InGaAsN layer sandwiched between n-type GaAs buffer (Si doped) and p-type InGaAsN layer ( $\mathrm{Zn}$ doped).

\begin{tabular}{|ll|}
\hline $\mathrm{p}+\mathrm{GaAs}: Z \mathrm{n}$ & $\sim 40 \mathrm{~nm}$ \\
\hline $\mathrm{p}$ InGaAsN:Zn & $\sim 30 \mathrm{~nm}$ \\
\hline $\mathrm{i}$ InGaAsN & $\sim 130 \mathrm{~nm}$ \\
\hline $\mathrm{n}$ GaAs:Si & $\sim 200 \mathrm{~nm}$ \\
\hline substrate GaAs:Si & $\sim 350 \mu \mathrm{m}$ \\
\hline
\end{tabular}

Fig. 1. Scheme of the epitaxial structure of p-i-n InGaAsN solar cell.

\section{Characterization OF INGAAsN EpIlayer}

Electrical and optical (photovoltage spectra) properties of the obtained epitaxial structure were determined using BioRad PN4300 electrochemical capacitance-voltage (EC-V) profiler [14]. Distribution of free carrier concentration is shown in Fig. 2. GaAs substrate doped with $10^{18} / \mathrm{cm}^{3}$ of electrons is visible on the right side in Fig.2. Substrate is followed (according to the growth direction) by GaAs:Si buffer layer with electron concentration in the range of 3 to $4 \times 10^{18} / \mathrm{cm}^{3}$, then undoped InGaAsN layer (some measurement points of hole and electron in the depth range of 70 to $200 \mathrm{~nm}$ ), then zinc doped layers: InGaAsN and highly doped GaAs (contact layer, with holes concentration of $5 \times 10^{19} / \mathrm{cm}^{3}$ ).

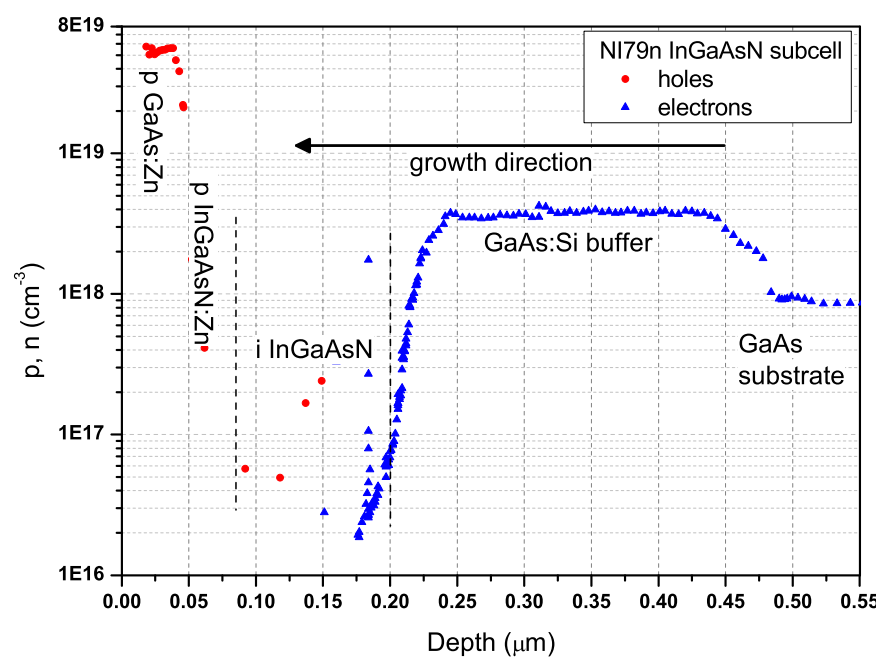

Fig. 2. Distribution of a free carrier concentration inside $p-i-n$ InGaAsN/GaAs epitaxial structure.
Results obtained from photovoltage spectroscopy (PVS) are depicted in Fig 3. Signals acquired from different depths

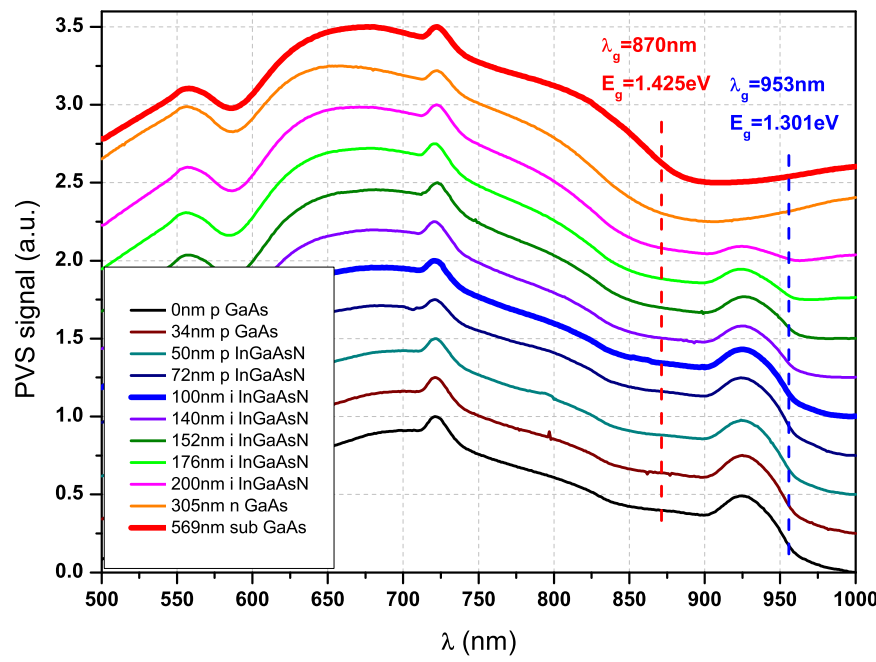

Fig. 3. Photovoltage spectra from different depths of InGaAsN/GaAs p-i-n epitaxial structure.

are shifted vertically for clarity. Thick blue line corresponds to signal from InGaAsN and GaAs layers while red line represents signal from GaAs substrate (note that red signal depth is greater than thickness of all epilayers). Characteristic local maximum in the spectral range of 900 to $970 \mathrm{~nm}$ represents the absorption in the InGaAsN epilayers. The absorption edge at $953 \mathrm{~nm}$ was determined from the plot of first derivative of PVS signal. It corresponds to the bandgap energy of InGaAsN of $1.301 \mathrm{eV}$, what is close to the value obtained from photoreflectance (PR) spectra presented in Fig. 4. Photoreflectance spectroscopy is a sensitive and very effective

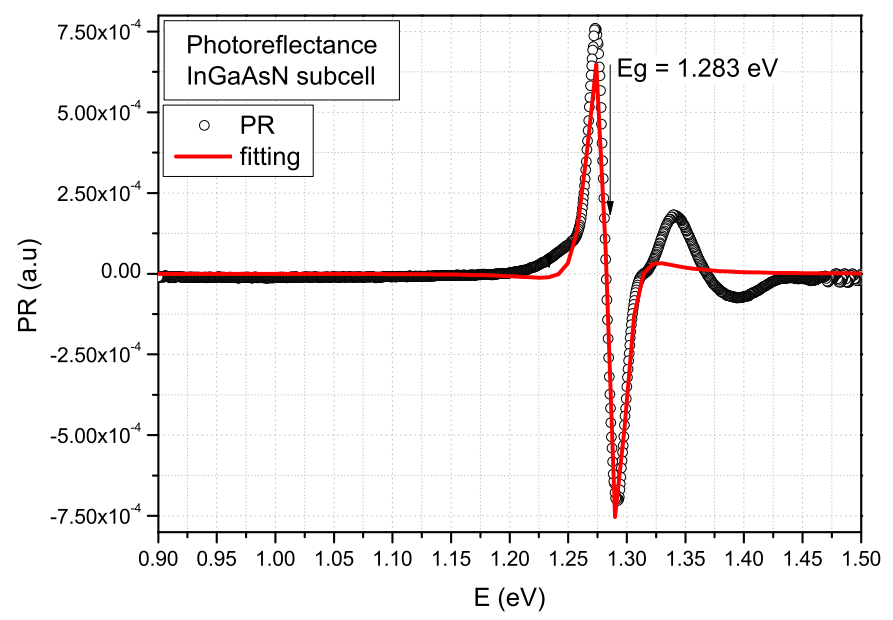

Fig. 4. Measured photoreflectance spectrum (dots) and simulated curve (red line) of InGaAsN-based subcell.

absorption-type technique which probe ground and excited states related optical transitions. Detailed information about PR method could be found elsewhere [15], [16], [17]. From photoreflectance technique the bandgap energy of InGaAsN layer was determined by comparison the measurement result with fitting curve. Obtained value of InGaAsN bandgap is 
$1.283 \mathrm{eV}$ and is smaller by $18 \mathrm{meV}$ from value obtained from PVS measurements.

\section{Technology of InGaAsN-BAsed Subcell}

Three types of the test solar cell devices were fabricated: using a standard photodetector configuration (shown in Fig. 5a, referred in this paper as A structure) and with transparent top electrode shown in Fig. 5b (labelled as B and C structures). In the case of the solar cell depicted in Fig. 5a (sample A) the
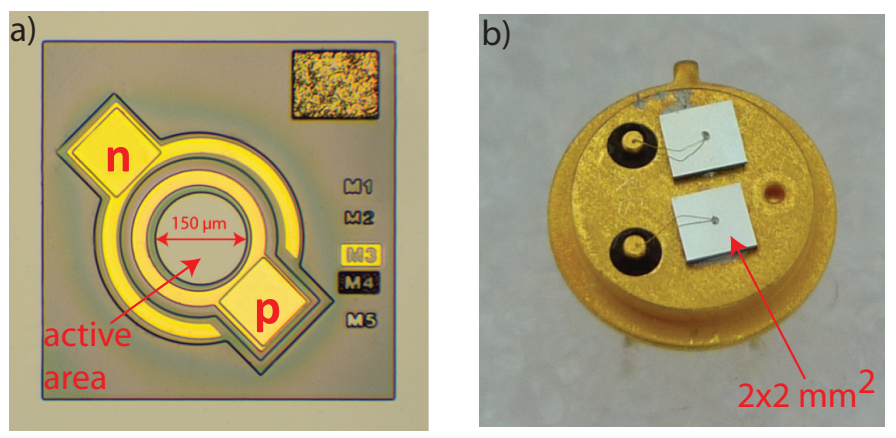

Fig. 5. Images of the fabricated test solar cell devices: a) typical detector configuration (structure A), b) structures with transparent top electrode (structures $\mathrm{B}$ and $\mathrm{C})$.

mesas were defined by combination of optical lithography and wet chemical etching. The metallic p-type ( $\mathrm{Pt} / \mathrm{Ti} / \mathrm{Pt} / \mathrm{Au})$ and n-type $(\mathrm{AuGe} / \mathrm{Ni} / \mathrm{Au})$ contacts were deposited under vacuum conditions on the top and around the mesa, respectively. In the case of solar cell shown in (Fig. 5b) the AuBe transparent metallization for $\mathrm{p}$-type and AuGeNi for n-type contact were deposited on the top and bottom side of the structure. The transparency of top p-type contact was determined to be $5 \%$ on the basis on transmission measurement (structure B). After that, second series of solar cell structures were fabricated with transparency of the top metallic electrode of $40 \%$ (structure C).

\section{Characterization of Solar Cell Devices}

Fabricated test solar cell structures were characterized by the means of J-V measurements under optical excitation using discreet laser diodes illumination and solar simulator AM 1.5 (with the possibility of sunlight concentration).

\section{A. Discreet Optical Excitation}

Firstly, the test solar cell structures (labelled as A) depicted in Fig. 5a were characterized. Three laser diodes emitting radiation with wavelengths of $\lambda_{1}=830, \lambda_{2}=904$ and $\lambda_{3}=980 \mathrm{~nm}$ were used as an optical excitation source. The optical power of the laser diodes was constant and equal to 10 and $20 \mu \mathrm{W}$, what corresponds to optical power densities of 113 and $226 \mathrm{~mW} / \mathrm{cm}^{2}$. Schemes of the solar cell structure and proper layers which absorb excitation radiation are presented in the insets of each J-V curve. In Fig. 6 the currentvoltage characteristics measured under an optical excitation of $\lambda=830 \mathrm{~nm}$ laser diode are depicted. Black and red curves represents the response under excitation of 10 and $20 \mu \mathrm{W}$. The used excitation wavelength of $\lambda=830 \mathrm{~nm}$ is mainly absorbed by GaAs cap layer, highlighted in red in Fig. 6 inset. Measured dark current is as low as $J_{\text {dark }}=384 \mathrm{nA} / \mathrm{cm}^{2}$. Obtained open circuit voltage $V_{O C}$ and conversion efficiency $\eta$ are equal to $0.667 \mathrm{~V}$ and $8.6 \%$ under $20 \mu W$ excitation power.

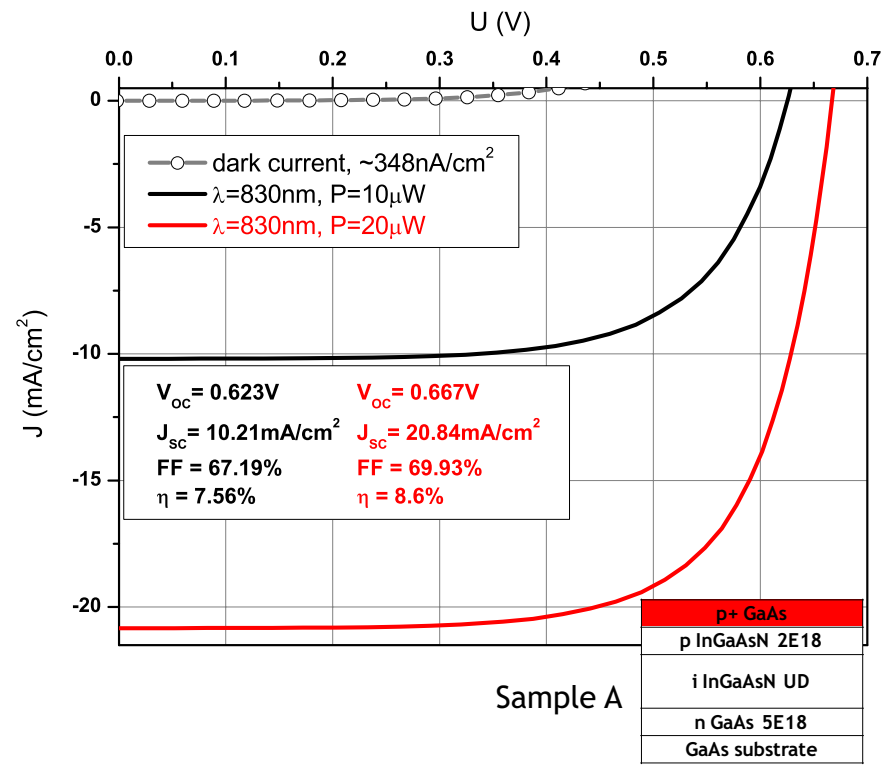

Fig. 6. J-V characteristics of the test solar cell (sample A) measured under an optical excitation of laser diode emitting radiation of $\lambda=830 \mathrm{~nm}$ and optical power of 10 (black curve) and $20 \mu W$ (red curve).

$\mathrm{J}-\mathrm{V}$ characteristics under the excitations of $\lambda=904 \mathrm{~nm}$ and $\lambda=980 \mathrm{~nm}$ laser diodes are shown in Fig. 7 and Fig. 8, respectively. Both used excitation wavelengths $\left(\lambda_{2}=904 \mathrm{~nm}\right.$ and $\lambda_{3}=980 \mathrm{~nm}$ what corresponds to energy of $1.371 \mathrm{eV}$ and $1.265 \mathrm{eV}$, respectively) are above gallium arsenide absorption edge (the window layer in investigated solar cell is consisted of GaAs), that means the measured current is in the majority generated in $\mathrm{p}$ and $\mathrm{i}$ InGaAsN layers (the wavelength of $\lambda=904 \mathrm{~nm}$ can be partially absorbed by GaAs due to broadening of the absorption edge caused by high doping).

Drop of short current $J_{S C}$, open circuit voltage $V_{O C}$ and conversion efficiency $\eta$ is observable in comparison to characteristics shown in Fig. 6. Simultaneously we observe an increase of fill factor $(F F)$ to $69.79 \%$ and $71.12 \%$ (under optical excitation of $\lambda=904 \mathrm{~nm}$ for 10 and $20 \mu W$ ) in comparison to $67.19 \%$ and $69.93 \%$ (under illumination of $\lambda=830 \mathrm{~nm}$ light for 10 and $20 \mu W$ optical power, respectively). This small increment of FF (shown in Fig. 9) means the investigated InGaAsN solar cell can exhibit better performance under the excitation of near infrared radiation $(\lambda=904 \mathrm{~nm})$. For excitation of $\lambda=980 \mathrm{~nm}$ we observe reduction of fill factor (in comparison to $F F$ achieved under $\lambda=904 \mathrm{~nm}$ ) from $69.89 \%(71.12 \%)$ to $61.29 \%(62.97 \%)$ under the excitation of $10(20 \mu W)$. The dependence of conversion efficiency on laser diode wavelength used as an excitation source is shown in Fig. 9.The shape of the curve which presents decrease of $\eta$ parameter is very similar to evolution curve of short circuit current, shown in Fig. 10. $J_{S C}$ decreases exponentially with wavelength used as an excitation source.

Taking the results recorded under the excitation of $\lambda=830 \mathrm{~nm}$ as a start point, we observe continuous decreasing of open circuit voltage $V_{O C}$, together with increasing the 


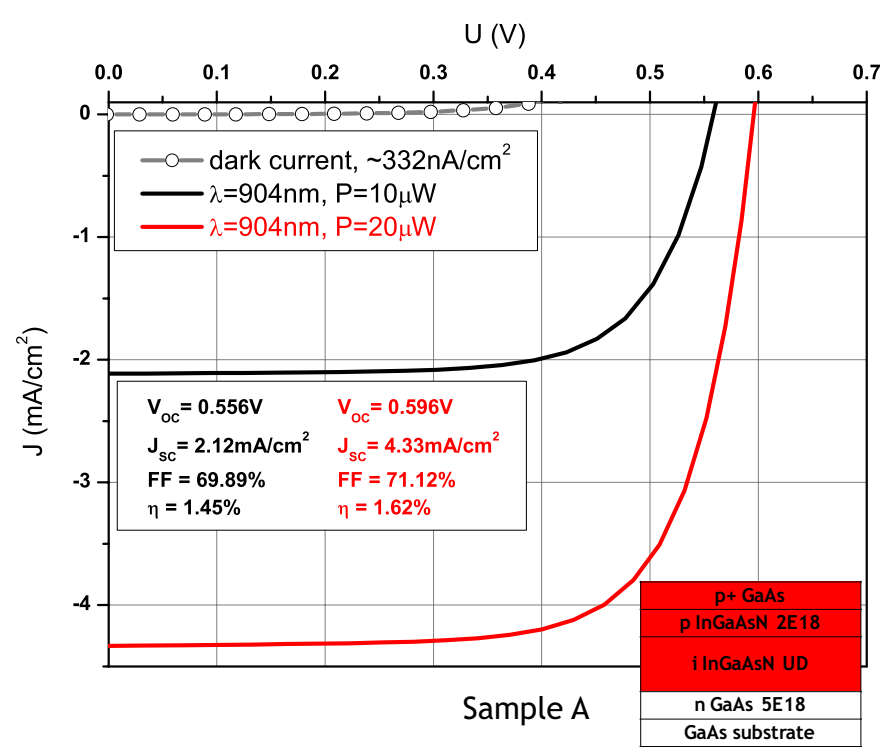

Fig. 7. J-V characteristics of the test solar cell (sample A) measured under an optical excitation of laser diode emitting radiation of $\lambda=904 \mathrm{~nm}$ and optical power of 10 (black curve) and $20 \mu W$ (red curve).

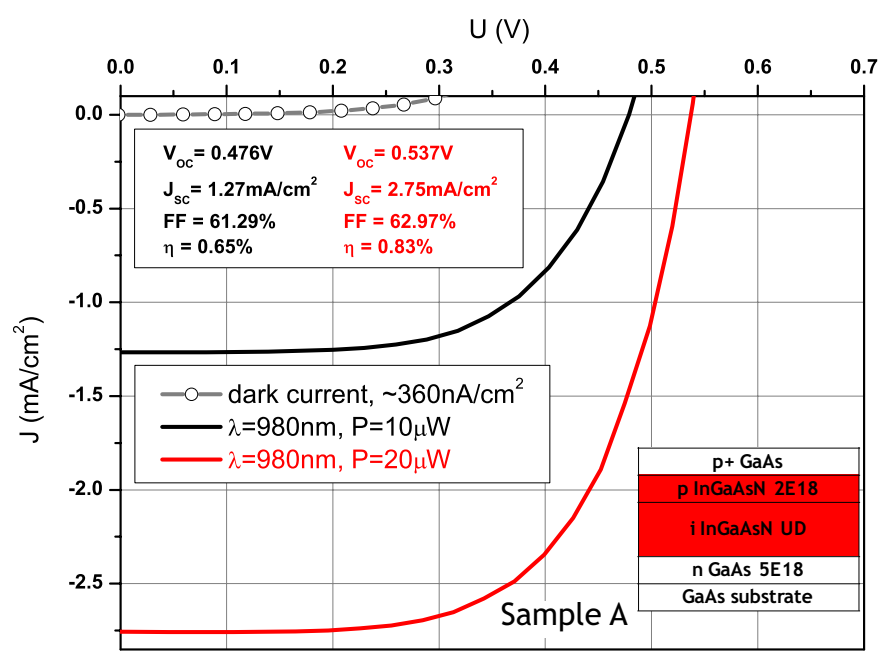

Fig. 8. J-V characteristics of the test solar cell (sample A) measured under an optical excitation of laser diode emitting radiation of $\lambda=980 \mathrm{~nm}$ and optical power of 10 (black curve) and $20 \mu W$ (red curve).

excitation wavelength - this situation is depicted in Fig. 11. The open circuit voltage drop ratios were equal to 0.960 and $0.867 \mathrm{mV} / \mathrm{nm}$ under 10 and $20 \mu \mathrm{W}$ excitation power, respectively. Lower value of decreasing ratio obtained under higher optical excitation testify that utilization of p-i-n InGaAsN solar cell under low concentrated sunlight may be promising (note that used excitation power of $20 \mu W$ responds to optical power density of $226 \mathrm{~mW} / \mathrm{cm}^{2}$ ).

\section{B. Sunlight Simulator}

Solar cell structures depicted in Fig. 5b were characterized by means of current-voltage measurements under sunlight (samples B and C). The Solar Light sunlight simulator (model 16S-002-300) was equipped with Fresnel lens which has resulted in 20-fold concentrating sunlight (20 suns,

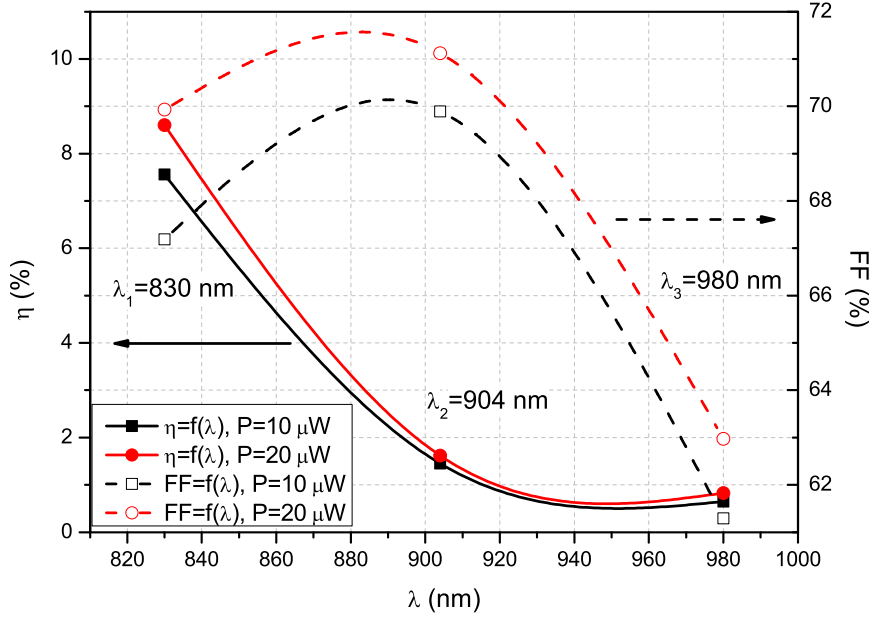

Fig. 9. Evolution of conversion efficiency and fill factor versus wavelength of used optical excitation. Black and red curves represent results obtained under excitations of 10 and $20 \mu W$, respectively.

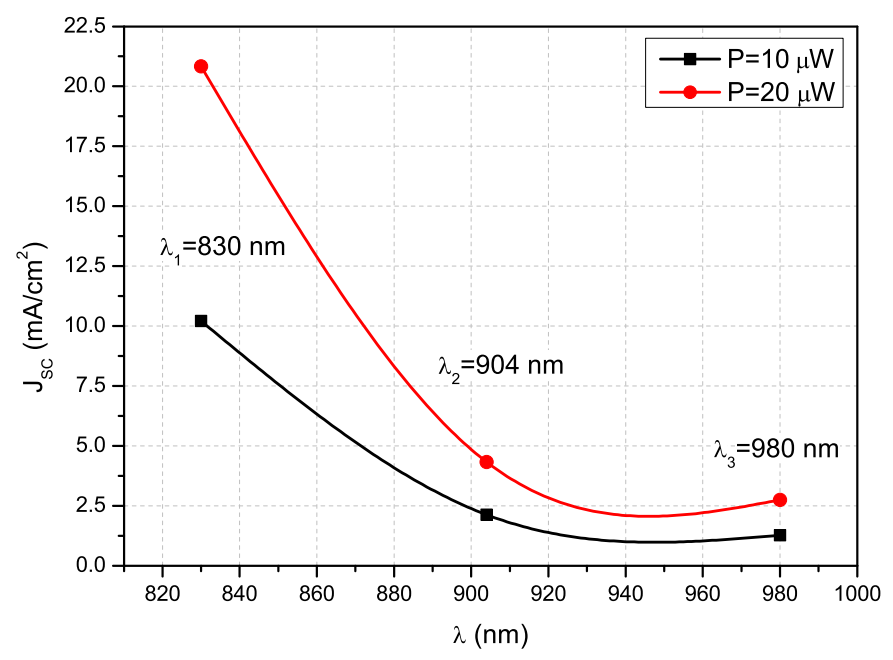

Fig. 10. Changes of short circuit current versus wavelength of used optical excitation. Black and red curves represent results obtained under excitations of 10 and $20 \mu W$, respectively.

$20 \times$ AM 1.5 spectrum) and cryostat system for SC temperature control. Keithley 237 and 2612A instruments were used for precise current and voltage measurements. Firstly the solar cell device with $5 \%$ transparent top contact was examined. Obtained J-V characteristics are shown in Fig. 12, then solar cells with $40 \%$ transparent metal contact were characterized under the same conditions (Fig. 13). In both figures grey lines with circles represent dark current, black curves were recorded under AM 1.5 spectrum, while red characteristics were obtained under concentrated sunlight $(20 \times$ AM 1.5).

The influence of top electrode transparency on electrical properties of InGaAsN solar cell is distinctly visible when we compare short circuit current densities $J_{S C}$. The improved AuBe top metallization of sample $\mathrm{C}$ is characterized by $40 \%$ transparency, it is 8-fold better than transparency of first fabricated solar cell (sample B, 5\% of transparency). It is exactly the same number as short circuit current proportion obtained for sample $\mathrm{C}$ and $\mathrm{B}$ (10.57 to $1.16 \mathrm{~mA} / \mathrm{cm}^{2}$ for 


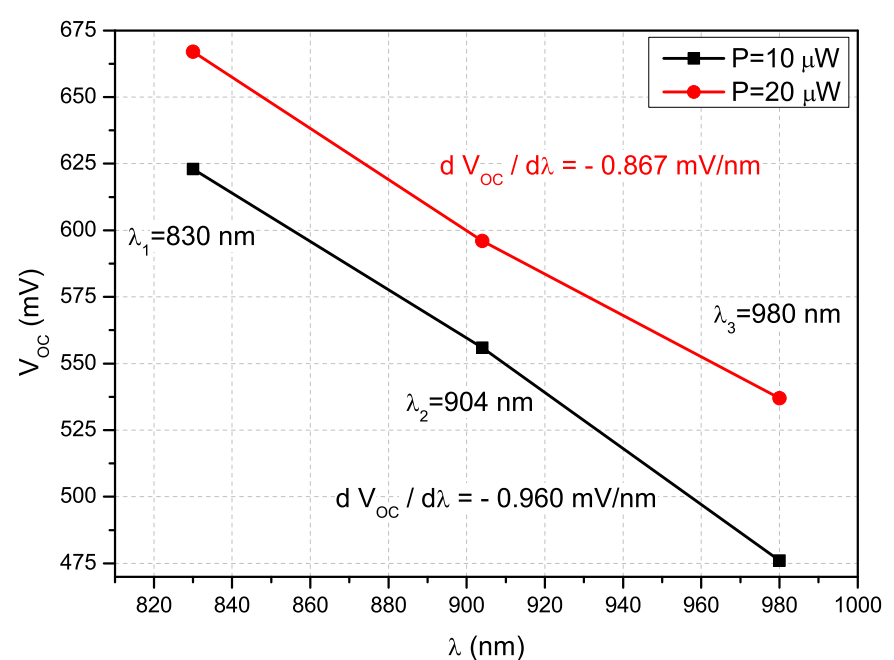

Fig. 11. Changes of open circuit voltage versus wavelength of used optical excitation. Black and red curves represent results obtained under excitations of 10 and $20 \mu W$, respectively.

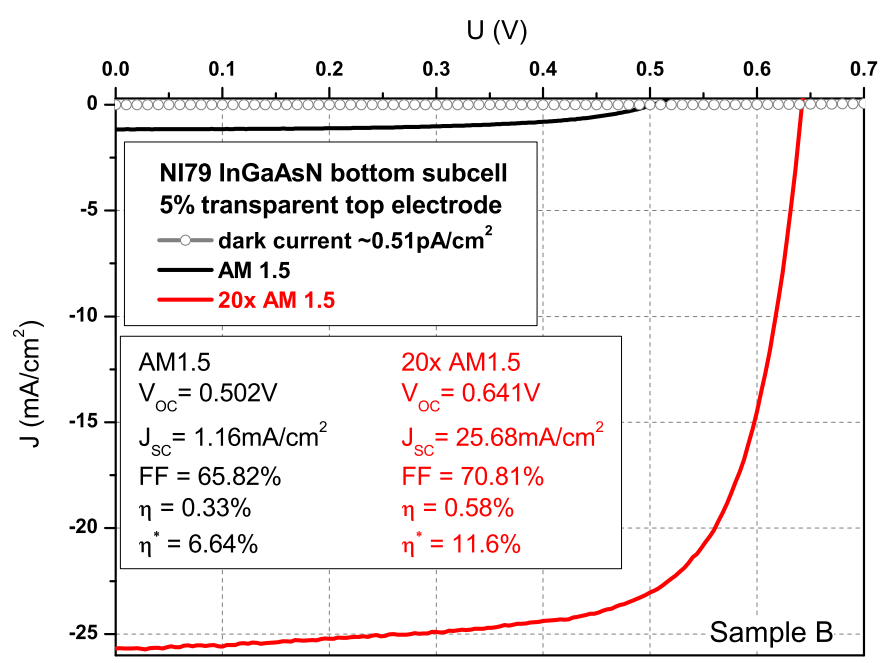

Fig. 12. J-V characteristics of the test solar cell with 5\% transparency, measured under sunlight (black curve) and concentrated sunlight (red curve)

AM 1.5 spectrum, and 201.88 to $25.68 \mathrm{~mA} / \mathrm{cm}^{2}$ under concentrated sunlight). The open circuit voltage $V_{O C}$ also changes with increasing transparency of top electrode. For sample B open circuit voltage $V_{O C}$ was equal to $502(641 \mathrm{mV}$ under concentrated sunlight) while for sample $C$ it was 603 $(697 \mathrm{mV}$ ). Improving the properties of the top electrode manifests 20 and $8.7 \%$ increase of $V_{O C}$ under AM 1.5 and concentrated excitation, respectively. Mentioned dependence between electrical parameters of SC and transparency of top electrode is not conserved in the case of conversion efficiency $\eta$ under AM 1.5 spectrum. The ratio of $\eta$ for sample $\mathrm{C}$ to $\eta$ of sample B exceeds 13 , but is equal to 8 for measurements under $20 \times$ AM 1.5 spectrum. Observed rising of conversion efficiency with increasing transparency of top electrode allow us to make an assumption and calculate the $\eta^{*}$ parameter for $100 \%$ transparent top contact. Obtained results of $\eta^{*}(11.6 \%$ for sample B and $11.71 \%$ for sample C) are compatible under concentrated sunlight. In the case of measurement under

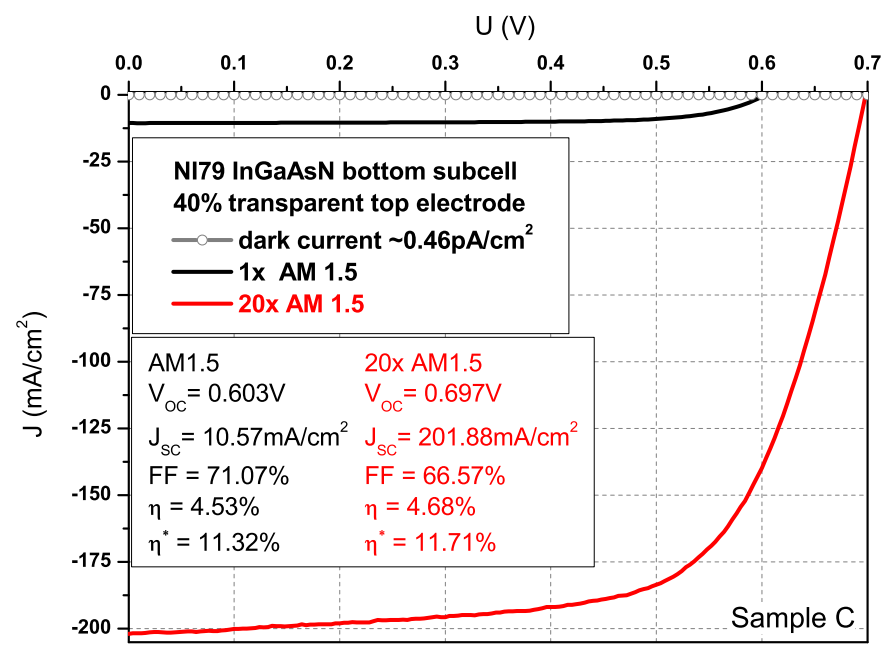

Fig. 13. J-V characteristics of the test solar cell with $40 \%$ transparency, measured under sunlight (black curve) and concentrated sunlight (red curve)

AM 1.5 spectrum the efficiency $\eta^{*}$ of $\mathrm{B}$ structure is almost twice smaller then $\eta^{*}$ of $\mathrm{C}$ structure. Fill factor (FF) of fabricated solar cells in the case of sample B increases with sunlight concentration, from 65.82 to $70.81 \%$. The situation is inversed for sample C, i.e. the FF decreases from 71.07 to $66.57 \%$.

After measurements of the J-V characteristics of B and C solar cells under two optical excitations, we compare obtained parameters with theoretical values. We calculate short circuit current density $J_{S C}$, open circuit voltage $V_{O C}$ and conversion efficiency $\eta$ according to (1-3) [18]:

$$
\begin{gathered}
J_{S C}^{C}=C J_{S C}, \\
V_{O C}^{C}=V_{O C}+\frac{k T}{q} \ln C, \\
\eta^{C}=\eta\left(\frac{F F^{C}}{F F}\right)\left(1+\frac{\frac{k T}{q} \ln C}{V_{O C}}\right),
\end{gathered}
$$

where $J_{S C}^{C}, V_{O C}^{C}, F F^{C}$ and $\eta^{C}$ are short circuit current, open circuit voltage, fill factor and conversion efficiency under concentrated sunlight; $C$ is a concentrator factor (in our case $C=20) ; k, T, q$ are Boltzmann's constant, temperature and elementary charge of electron, respectively. Calculated and measured parameters of SCs are collected in Table I.

TABLE I

COMPARISON OF CALCULATED AND MEASURED PARAMETERS OF INGAASN SOLAR CELL (SAMPLE B AND C) UNDER CONCENTRATED SUNLIGHT (20XAM 1.5)

\begin{tabular}{ccc}
\hline \hline Solar cell parameter & Structure B & Structure C \\
\hline$J_{S C}$ theory $\left(\mathrm{mA} / \mathrm{cm}^{2}\right)$ & 23.2 & 211.4 \\
$J_{S C}$ measured $\left(\mathrm{mA} / \mathrm{cm}^{2}\right)$ & 25.68 & 201.88 \\
$V_{O C}$ theory $(\mathrm{mV})$ & 579 & 680 \\
$V_{O C}$ measured $(\mathrm{mV})$ & 641 & 697 \\
$\eta^{*}$ theory $(\%)$ & 8.25 & 11.96 \\
$\eta^{*}$ measured $(\%)$ & 11.6 & 11.71 \\
\hline \hline
\end{tabular}


Short circuit current determined from $\mathrm{J}-\mathrm{V}$ curves demonstrates linear dependence on sunlight concentration, according to (1). $J_{S C}$ obtained for sample B is higher than calculated, while for sample $\mathrm{C}$ is smaller (about $4.7 \%$ smaller than theoretical prediction). For both samples open circuit voltage obtained from $\mathrm{J}-\mathrm{V}$ characteristic is bigger than calculated using (2), where for sample B the difference is significant and as high as $82 \mathrm{mV}$. The conversion efficiency of sample B calculated on the basis of (3) is considerably smaller than determined from $\mathrm{J}-\mathrm{V}$ measurement. This divergence is mainly caused by big $(82 \mathrm{mV})$ difference of open circuit voltages: theoretical and experimental. In the case of structure $C$ the agreement of experimental value with calculated $\eta^{*}$ is very good.

\section{CONCLUSION}

In this paper the epitaxial growth, optical and electrical characterization of InGaAsN epilayers and fabrication process of InGaAsN-based subcell devices were presented and discussed. We showed and analyzed current-voltage characteristics of fabricated InGaAsN subcells under excitation of three laser diodes and solar cell simulator. Finally we discussed and analyzed the changes of solar cell parameters with increasing excitation wavelength (sample A) and sunlight concentration (in the case of sample B and C).

\section{REFERENCES}

[1] W. Shockley and H. J. Queissery, "Detailed Balance Limit of Efficiency of p-n Junction Solar Cells," J. Appl. Phys., vol. 32, pp. 510-519, 1961

[2] G. Conibeer, "Third-generation photovoltaics," Materials Today, vol 10, pp. 42-50, 2007.

[3] S. P. Philipps et al., "Present Status in the Development of IIIV Multi-Junction Solar Cells," in Next Generation of Photovoltaics, A. Cristobal, A. Marti Vega, L. Luque (eds), Springer Series in Optical Sciences, Vol. 165, pp. 1-22, 2012.

[4] C. B. Honsberg, S. P. Bremner and R. Corkish, "Design trade-offs and rules for multiple energy level solar cells," Physica E: Low-dimensional Systems and Nanostructures, vol. 14, pp. 136-141, 2007.
[5] T. Trupke, M. A. Green and P. Würfel., " Improving solar cell efficiencies by down-conversion of high-energy photons," J. Appl. Phys., vol. 92, pp. 1668-1674, 2002.

[6] H.-Q. Wang et al., " Rare-Earth Ion Doped Up-Conversion Materials for Photovoltaic Applications," Advanced Materials, vol. 23, pp. 26752680, 2011.

[7] H. A. Atwater and A. Polman, "Plasmonics for improved photovoltaic devices," Nature Materials, vol. 9, pp. 205-213, 2002.

[8] R. T. Ross and A. Nozik, "Efficiency of hot-carrier solar energy converters," J. Appl. Phys., vol. 53, pp. 3813-3818, 1982.

[9] M. Weyers, M. Sato and H. Ando, "Red Shift of Photoluminescence and Absorption in Dilute GaAsN Alloy Layers," Jpn. J. Appl. Phys, vol. 31(7A), pp. L853-L855, 1992.

[10] M. Kondow, K. Uomi, A. Niwa, T. Kitatani, S. Watahiki and Y. Yazawa, "GaInNAs: A Novel Material for Long-Wavelength-Range Laser Diodes with Excellent High-Temperature Performance," Jpn. J. Appl. Phys, vol. 35, pp. 1273-1275, 1996.

[11] B. Ściana et al., "Influence of the AP MOVPE process parameters on properties of $(\mathrm{In}, \mathrm{Ga})(\mathrm{As}, \mathrm{N}) / \mathrm{GaAs}$ heterostructures for photovoltaic applications," Proceedings of SPIE, vol. 8902, pp. 89020J-1 - 89020J-8, 2013.

[12] B. Ściana et al., "MOVPE growth of AIIIBV-N semiconductor compounds for photovoltaic applications," Cryst. Res. Technol., vol. 47, pp. 313-320, 2012.

[13] D. Radziewicz et al., "Influence of the MOVPE growth parameters on the properties of InGaAsN/GaAs MQW structures for solar cells application," ASDAM 2012 - Conference Proceedings: The 9th International Conference on Advanced Semiconductor Devices and Microsystems, pp. 123-126, 2012

[14] "PN4300PC Electrochemical C-V Profiler with Photovoltage Spectroscopy," Operating Manual, Accent Semiconductor Technologies Inc. issue 2, September 2000.

[15] F. H. Pollack and H. Shen, "Photoreflectance characterization of semiconductors and semiconductor heterostructures," Journal of Electronic Materials, vol. 19, pp. 399-406, 1990.

[16] J. Misiewicz, P. Sitarek, G. Sek and R. Kudrawiec, "Semiconductor heterostructures and device structures investigated by photoreflectance spectroscopy," Materials Science-Poland, vol. 21, pp. 263-320, 2003

[17] E. Canovas et al., "Photoreflectance analysis of a GaInP/GaInAs/Ge multijunction solar cell ," Appl. Phys. Lett., vol. 97, pp. 203504(1)203504(3), 2010.

[18] J. Gray, "The Physics of the Solar Cell," in Handbook of Photovoltaic Science and Engineering, Second Edition, A. Luque and S. Hegedus (eds), John Wiley \& Sons, pp. 82-129, 2011. 